

\title{
SaaS for Education: A Case Study of Google Apps in Software Engineering Class
}

Pradorn Sureephong, Apitchaka Singjai

\section{To cite this version:}

Pradorn Sureephong, Apitchaka Singjai. SaaS for Education: A Case Study of Google Apps in Software Engineering Class. 12th IFIP International Conference on Product Lifecycle Management (PLM), Oct 2015, Doha, Qatar. pp.631-639, 10.1007/978-3-319-33111-9_57 . hal-01377491

\section{HAL Id: hal-01377491 \\ https://hal.inria.fr/hal-01377491}

Submitted on 7 Oct 2016

HAL is a multi-disciplinary open access archive for the deposit and dissemination of scientific research documents, whether they are published or not. The documents may come from teaching and research institutions in France or abroad, or from public or private research centers.
L'archive ouverte pluridisciplinaire HAL, est destinée au dépôt et à la diffusion de documents scientifiques de niveau recherche, publiés ou non, émanant des établissements d'enseignement et de recherche français ou étrangers, des laboratoires publics ou privés. 


\title{
SaaS for Education: A Case Study of Google Apps in Software Engineering Class
}

\author{
Pradorn Sureephong ${ }^{1}$, Apitchaka Singjai ${ }^{2}$, \\ College of Art Media and Technology, Chiang Mai University, ChiangMai, Thailand \\ 1 pradorn@camt.info, ${ }^{2}$ apitchaka@ camt.info
}

\begin{abstract}
Cloud computing technology in higher education brings cost efficiency and flexibility into the organizations: software as a service (SaaS) solutions require low infrastructural investments and migrate IT resources to the Internet. Adapting to the rapidly changing environment, students require new technology, new methods, new instruments and even new learning techniques. Google apps is the choice for the students. This research aims to assess the Google apps that were selected from the previous works. The researchers applied Google apps in software engineering class of College of Art Media and Technology (CAMT).
\end{abstract}

Keywords: Cloud Computing, Google apps, Learning Cloud Services, SaaS, Software Selection

\section{Introduction}

Cloud computing is one of the applicable technologies which can improve end-user productivity and reduce driven-overhead by offering services. Cloud computing technology has been widely defined in many different ways. Cloud computing not provides only services through internet but also the provision of several commodities "as-a-service" [1, 2]. On another word, cloud computing can provide the provisioning services such as Infrastructure as a Service (IaaS), Platform as a Service (PaaS), Software as a Service (SaaS), and Business Process as a Service (BPaaS).

Cloud computing is also information technology communication for education environment $[3,4]$. The students can get the benefits from this technology, especially, Software as a Service (SaaS) which can improve flexibility and accessibility [3, 5]. Cost cutting is a key benefit because the users don't have to install the software on their own computer. SaaS change the way how to deliver the software to customers because the customers can access the services through internet [6]. The organizations which are interested in the SaaS model would like to subscribe SaaS more than develop a new one [7]. If the organizations would like to apply SaaS, they need to select appropriate services. Different SaaS providers propose different services to their educational solution. They offer not only different services; but also, different solutions. On the other hand, these solutions are not completely different, they still have common services. These reasons lead competition among SaaS providers occur. SaaS providers are growing up rapidly due to continuous growing of cloud computing 
technology. Consequence, SaaS vendors can offer several alternative solutions that able to meet SaaS user needs. Normally, SaaS providers provide standardized services to subscribers but the subscribers always have unique requirements for their own businesses. If the standardized services could not fulfill their requirements, customization and configuration are applicable [6,8]. Selection issue comes up with decision making. The decision making applies the prioritization to clearly define the selection $[5,9]$.

Higher education and cloud computing bring cost effectiveness to the educational institution [12]. For the higher education, the cost of being in this level is increasing compare to the lower level but the university's budget is decreasing $[10,11]$. The students in the higher education also ask for improving the teaching methods, new technologies, new instrument and new learning technique [10, 12]. Some education institutions do not have resources or infrastructure to support their students $[4,13]$. In order to the needs of student and the problems of education institutions, adapting software services can help with this issue. Reusing software service leads us more efficient and more adaptable to the needs [10,11]. Moreover, this research also adopt learning cloud services framework to build up the service checklists of students because this framework is under the perspective of learners [14].

This research aims to assess the Google apps that were selected from the previous work. There are two previous works that have been related to this research paper: provider selection and service prioritization. Recommendation matrix for selecting education cloud service providers: configuration and customization perspectives, is applied to select the cloud provider [15]. The imperativeness of services is prioritized by using combined techniques between 100 dollars test and grouping [16].

In the following, we begin by showing the literature review of software selection process that we apply for the research methodology (Section 2). Next, we explain how this research were conducted (Section 3), this is followed by a results and discussions (Section 4) and conclusion (Section 5).

\section{Software Selection Process}

In 2009 Syed Ahsan Fahmi and Choi summarized the existing methods which are OTSO, CSSP, CRE and CBR [17]. The first one, Off-The Shelf-Option (OTSO) is the general method to choose the component. The aim of this method is evaluate the existing component-of-the-shelf (COTs) based on the requirement of the organization. This method consists of 6 tasks which are searching, screening, evaluation, analysis, deployment and assessment [18]. The second one, COTS Software Selection Process (CSSP), the aim of this method is to choose the right COTs for the organization. The important thing is this method has defined the criteria of input and output of each task clearly. The method is composed of 6 tasks which are evaluation team, goal identify, plan, filtering from vendor information, filtering from vendor demonstration and documentation [19]. The third one, Cots-Based Requirement Engineering (CRE) is the systematic method and reusable follow the requirements. The highlight of this method is supporting non-functional requirement to choose software. The main point of this method is the requirement which meets the customer will be kept and others requirements are eliminated [20]. The last one, Cots-Based Requirement Engineering 
(CBR), contains 4 steps which are retrieve, reuse, revise and retain. This method suitable with the organization where have experience about choosing the software before, therefore; the organization can select the software base on the experience [21].

\begin{tabular}{|c|c|c|c|c|}
\hline OTSO & CSSP & CRE & CBR & Conclusion \\
\hline Searching & \multirow{2}{*}{ Identify } & Search & \multirow{2}{*}{ Retrieve } & \multirow{3}{*}{ Selection } \\
\hline Screening & & \multirow{2}{*}{$\begin{array}{l}\text { Candidate } \\
\text { Product list }\end{array}$} & & \\
\hline Evaluation & Filtering & & Revise & \\
\hline Analysis & Analyze & Requirements & \multirow{3}{*}{ Retain } & Analysis \\
\hline Deployment & \multirow{2}{*}{ Document } & \multirow{2}{*}{ Feedback } & & \multirow{2}{*}{ Assessment } \\
\hline Assessment & & & & \\
\hline
\end{tabular}

Fig. 1. The Common Software Selection Process

Each software selection process has own appropriated context. OTSO is proper with the organization where decision making depends on authorized people. CSSP I suitable for the organization where explicit results of each selection phase is required. CRE is for the organization where they concern about users; satisfaction. CBR fits with the organization where they have experiences about choosing software. On the other hand, these software selection processes have the phases in common. As a result researcher classifies the common task of each method into 3 tasks which are selection, analysis and assesment as shown in Fig. 1. The Eliminate, Combine Rearrange, and Simplify (ECRS) method is adapted to conclude the research methodology in this research [22]. Selection is about searching or identifying what kind of software that we need. Analysis is the designing process that we could filter or manage the software from the previous process. Assessment is the process that validate the selected software.

\section{Research Methodology}

The research methodology consists of three main processes: provider selection process, service analysis process and software as a services assessment process. In the process of selection, the principles of the learning cloud service framework are utilized. In the service analysis process, we use two techniques of prioritization: the 100 dollars test and grouping. This process classifies the services into groups by using $\mathrm{K}$-means algorithm. In the course of software-as-s-service assessment, a requirement document is created to build up the prototype of the learning supported system for students. In this research we focus on the third process (SaaS Assessment) as shown in Fig.2., there are 3 phases which are matching, designing and applying. Firstly, matching phase, the prioritized services and cloud service provider are matched. Secondly, Designing phase is the phase that rank the selected services into the web portal. Lastly, these selected services should be applied in the organization. 


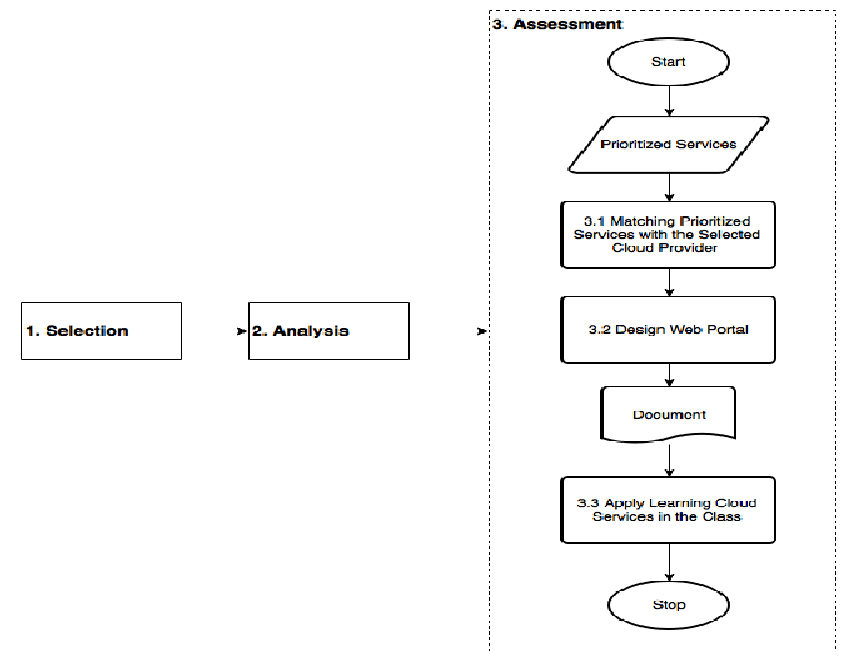

Fig. 2. The Overview of Proposed Framework

Fig. 2. Describes the proposed framework. The first step is about selection provider through recommendation matrix. The result is an appropriate provider for the organization. The second step is analyzing the services of the provider by adopting the learning cloud service requirement to classify these services into groups. After that let the student prioritize the services follow 100 dollars test technique. The K-means algorithm applied to identify the proper number of group of the services. The prioritized services are formed into the document and the SaaS is assessed by the students in the last step.

\subsection{Matching Prioritized Services with the Selected Cloud Provider}

The selected cloud provider in this research is Google. In addition, Google apps are the services that we will match with the prioritized services. The prioritized services are from learning cloud service checklist. The requirements of service checklist adopt the requirements of learning cloud service framework. 5 categories of services are personal learning, community learning, collaborative learning, communicative learning, and multi-rich material learning.

\subsection{Designing Web Portal}

The document is written to communicate with developer who can create the prototype and let the student try the collection of services that has been chosen. Regarding the matching prioritized services with the selected cloud provider, we know which Google apps will be used. Moreover, each service and each category has own priority. With the priority, we can design the web portal. 


\subsection{Applying Learning Cloud Services in the Class}

First of all, train the students about how to use the Google apps that has been chosen. And then, let the students try these Google apps for one semester .After that, the students could return their feedback. There are 5 scales that the student can assign to each services about their usability. The score is 5 if that services is strongly useful for their learning. The score is 4 if that services is useful for their learning. The score is 3 if that services is not affected for their learning. The score is 2 if that services is useless for their learning. The score is 1 if that services is strongly useless for their learning.

\section{$4 \quad$ Result and Discussion}

The researchers applied this approach in College of Art Media and Technology (CAMT) with 42 students. For the provider selection process, Google were chosen as a provider because Google got the highest recommendation score from the recommendation matrix for selecting education cloud service provider [16]. This matrix is built up from the configuration and customization and take the provider who provide the services for educational institution to be candidate. Moreover, the criteria of this matrix are from learning cloud service framework. Next the service analysis process apply two prioritization techniques. Numerical assignment technique allows students to answer 'need' and 'no need' and 'no opinion'. cumulative voting technique or 100 dollars technique is adapt in 'need' answer by allowing the student spend money on service that they need and they can spend money 100 dollars in total. Then the prioritized services are from the service analysis process. Services are classified into 3 groups as follows: critical, standard and optional. The optional services are not applied in this research.

\subsection{Matching Prioritized Services with the Selected Cloud Provider}

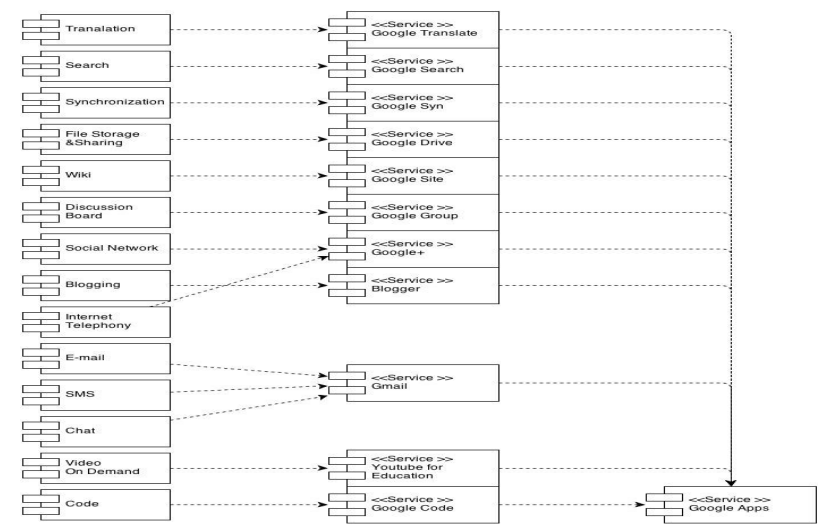

Fig. 3. The Diagram for the Learning Support Services 
Fig. 3. is showing the relation between the services and software as a service of the provider. There are 14 learning cloud services as follows: translation, search, synchronization, file storage and sharing, wiki, discussion board, social network, blogging, internet telephony, e-mail, sms, chat, video on demand, and code. However, only 11 Google apps that matched with the selected cloud learning services which are Google translate, Google search, Google Syn, Google drive, Google site, Google group, Google+, Blogger, Gmail, Youtube for education, Google code. Google+ could match both social network and internet telephony. Gmail could provide services for e-mail, sms and chat.

\subsection{Designing Web Portal}

The result prioritization can design the webpage. The services in critical and standard group are applied in the learning support web portal as shown in Fig. 4. Five categories of services are also rank from the most important category to the least important category, personal learning, collaborative learning, social community learning, communicative learning, and multimedia-rich material respectively.

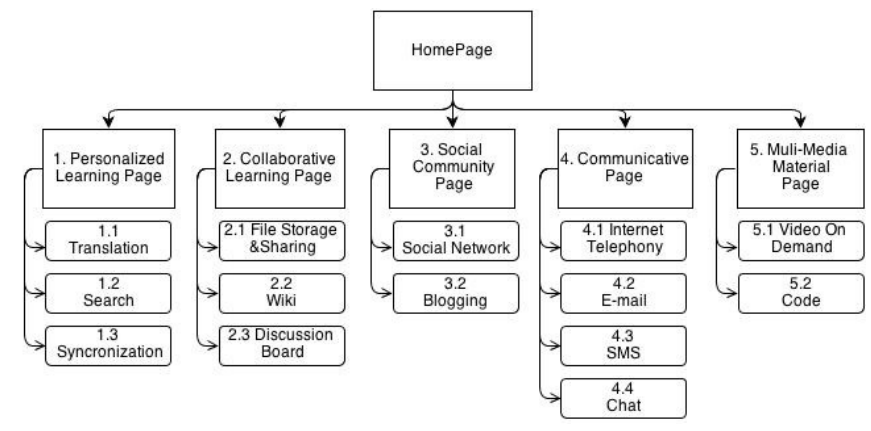

Fig. 4. The Overview of Learning Support Web Portal

The services in each category is classify into two groups which are the critical and standard. Firstly, personal learning has synchronization in standard group and other services in critical group. Secondly, collaborative learning has file storage \&sharing in critical group and other services in standard group. Thirdly, social community learning has social network service in critical group and blogging service in standard group. Fourthly, communicative learning has internet telephony in critical group and other services in standard group. Lastly, multi-media rich material has only services in the standard group. 


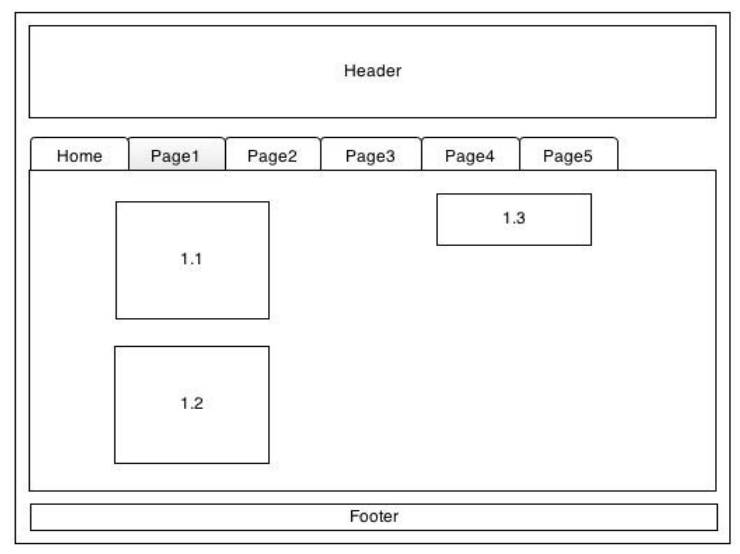

Fig. 5. The Personalized Learning Page

Fig. 5. illustrates the example of the personalized learning page which arranges the services in the critical group to the left hand-side and arrange the services in the standard group in the right-hand. Moreover, the priority of each page are also prioritized from the amount of money that the students spent from the service analysis phase with the 100-dollar technique.

\subsection{Applying Learning Cloud Services in the Class}

For the feedback, 41 students from 42 students respond about the software as a service that the researchers select for them in Table1. The researchers provide an online questionnaire to let them evaluate each selected service about the supportedusability for their learning.

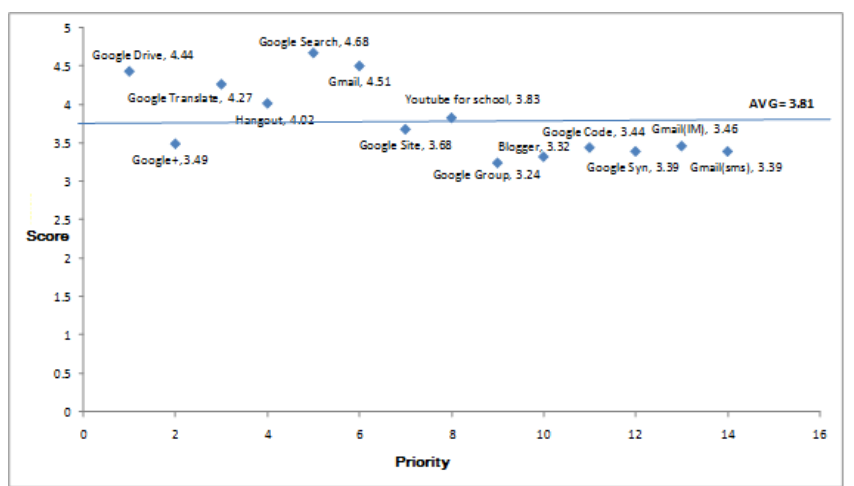

Fig. 6. The Feedback from the students 
Fig.6. demonstrate the feedback of students about the each selected service's supported-usability for their learning. The horizontal axis shown the priority of each services, while the vertical axis represent the feedback score of each service. The priority ranked from the heist priority to the lowest priority which are number 1 and number 14 respectively. The average score of these services are 3.81 .

The trend of the students' feedback is the same direction like the prioritization services. Most of SaaS from the critical group got the score over average, except Google+. In this case, the integration approach is recommended; the organization can apply another SaaS to the social network approach because there are many social networking. Whereas Most of SaaS from the standard group got the score under average, only Youtube for education that slightly greater that the average. In this case, we found learning by video on demand is suitable for the software engineering class of CAMT. .

\section{Conclusion}

Applying SaaS in the classroom could enhances the learning method of the students. This paper tries to prove that the selected learning cloud services from the previous work could make the student satisfying. The process starts from matching the prioritized services with the selected cloud provider, and then designing the web portal and letting the students try before give the feedback. The limitation of this research is applying the services from only one cloud provider. For the future work, the researchers can use the integration approach with various sources of services.

\section{References}

[1] Accorsi R.: Business Process as a Service: Chances for Remote Auditing. In: The 35th IEEE Computer Software and Applications Conference Workshops, pp. 398-403. Munich, Germany (2011)

[2] van den Heuvel, W.J.: Leveraging Business Process as a Service with Blueprinting. In: IEEE 13th Conference on Commerce and Enterprise Computing (CEC), pp. 225--225. . Luxembourg (2011)

[3] Xin, T., Yongbeom,K.: Cloud Computing for Education: A Case Study of Using Google Docs in MBA Group Project. In International Conference on Business Computing and Global Informatization (BCGIN), pp. 641-644. (2011)

[4] Pocatilu, P.: Cloud Computing Benefits for E-learning Solutions, Oeconomics of Knowledge, vol. 2(1), pp. 9-14. (2010)

[5] Godse, M., Mulik, S.: An Approach for Selecting Software-as-a-Service (SaaS) Product. In: IEEE International Conference on Cloud Computing, pp. 155-158. Bangalore (2009)

[6] Nitu: Configurability in SaaS (software as a service) applications. In: Proceeding of the 2nd Annual India Software Engineering Conference. Pune, India (2009)

[7] Hirzalla, M.: Realizing Business Agility Requirements through SOA and Cloud Computing. In: 18th IEEE International Requirements Engineering Conference (RE), pp. 379-380. (2010)

[8] Wei S., Xin, Z., Chang Jie, G.,, Pei, S., Hui, S.: Software as a Service: Configuration and Customization Perspectives. In: Congress on Services Part II, pp. 18-25. (2008) 
[9] Aasem, M., Ramzan, M., Jaffar, A.: Analysis and optimization of software requirements prioritization techniques. In: International Conference on Information and Emerging Technologies (ICIET), pp. 1--6 (2010)

[10] Mircea, M.: SOA, BPM and Cloud Computing: Connected for Innovation in Higher Education, In: International Conference on Education and Management Technology (ICEMT), pp. 456--460 (2010)

[11] Guin, R. B., Chakrabarti, S., Tarafdar, C., Mandal, S., Banerjee, S., Biswas, U.: A smart Architectural Concept for making of University Educatin System using Cloud Computing Paradigm. In: World Congress on Information and Communication Technologies (WICT), pp. 48-52(2011)

[12] Vitkar, S.: Cloud Based Model for E-learning in Higher Education, In: International Journal of Advanced Engineering Technology, vol 3(4), (2012)

[13] Peng, S.C., Brad, W.: Strategies for e - education. In: Industrial and Commercial Training, vol 35(5): pp. 196-202, (2003)

[14] Cheng-Sian, C., Tzung-Shi, C., Hsiu-Ling, H.: The Implications of Learning Cloud for Education: From the Perspectives of Learners. In: IEEE Seventh International Conference on Wireless, Mobile and Ubiquitous Technology in Education (WMUTE), pp. 157$166,(2012)$

[15] Apitchaka S., Sureepong, P.: Prioritization Technique for Learning Cloud Services, In: International Journal of Intelligent Computing and Cybernetics, vol 8(3), (2015)

[16] [18][15] Apitchaka Singjai S., and P. Sureepong, P.: Recommendation Matrix for Selecting Education Cloud Service Providers: Configuration and Customization Perspectives, In: The 6th Conference on Software, Knowledge, Information Management and Applications, Chengdu, China, (2012)

[17] Fahmi, S.A., Ho-Jin, C.: A study on software component selection methods. In 11th International Conference on Advanced Communication Technology, pp. 288-292, (2009)

[18] James A. Constantine, Solak, S.: SysML Modeling of Off-the-Shelf-Option Acquisition for Risk Mitigation in MilitaryPrograms. In: System Engineering, Vol 13(1), pp. 80-93, (2010)

[19] Lin, H., Lai, A., Ullrich, R., Kuca, M., Shaffer-Gant, J., Pacheco, S., Dalton, K., McClelland, K., Watkins, W., Khajenoori, S.: COTS Software Selection Process, SANDIA REPORT (2006)

[20] Alves, C., Castro, J.: CRE: A Systematic Method for COTS Components Selection, In: XV Brazilian Symposium on Software Engineering (SBES) Rio de Janeiro, pp. 193207, Brazil (2001)

[21] Aamodt A., Plaza, E.: Case-Based Reasoning: Foundational Issues, Methodological Variations, and System Approaches. In: AI Communications, vol 7(1), pp. 39-59, (2001)

[22] Haitao S., Jinfeng H.,Haiqing, G.: Submerged Arc Welding Procedure Improvement based on Human-Machine Operation Analysis, In: International Conference on Information Management, Innovation Management and Industrial Engineering,pp. 486-489, (2010) 